\title{
Elder Abuse: A National Disgrace ${ }^{1}$
}

Carolyn S. Wilken²

\section{Overview}

Elder abuse has been described as a national disgrace.

The National Center on Elder Abuse (NCEA) estimates that between 820,000 and 1,860,000 older Americans are victims of abuse each year. Elder abuse is also a disgrace to families. That's because elders are most often abused in their own homes. And, family members commit most identified cases of elder abuse.

Like child abuse and spouse abuse, elder abuse is under-reported. The numbers of abuse cases are probably much higher. If elder abuse is going to stop, we must all be aware of the signs of abuse, and we must be willing to take action to stop the abuse.

\section{What is Elder Abuse?}

But what is elder abuse? Who is most at risk of being abused, or becoming an abuser? This publication answers those questions by describing:

* the categories and types of abuse,

* risk factors of abuse,

* resources for families and caregivers, and/or

* how to report abuse.

\section{Categories of Abuse}

The National Center on Elder Abuse (NCEA) has identified three basic categories of elder abuse:

- abuse;

- $\quad$ exploitation; and

- neglect.

Abuse includes physical, emotional, and sexual abuse.

Exploitation is the misuse of the elderly persons resources for personal or financial benefit.

Neglect, is the refusal or failure to provide for the basic needs of an elderly person.

All three categories of abuse can occur in the home or in an institutional setting.

1. This document is FCS2192, one of a series of the Department of Family, Youth and Community Sciences, Florida Cooperative Extension Service, Institute of Food and Agricultural Sciences, University of Florida: First published: June 1989. Reviewed: August 1999, March 2002. Revised: December 2002. Please visit the EDIS Web site at http://edis.ifas.ufl.edu

2. Carolyn S. Wilken, Ph.D., associate professor, Family Life, Department of Family, Youth and Community Sciences, Cooperative Extension Service, Institute of Food and Agricultural Sciences (IFAS), University of Florida, Gainesville FL 32611. 


\section{Domestic elder abuse}

Domestic elder abuse occurs in family settings. Usually, a family member is the abuser. Adult children are the abusers in nearly half of reported domestic elder abuse cases. Spouses are the abusers in one out of five domestic abuse cases.

\section{Institutional elder abuse}

Institutional abuse most frequently occurs in a long-term care facility such as a nursing home, group home, foster home, unlicensed facilities, or board-and-care homes. Abuses in institutions may seem more common than domestic elder abuse, but that is because institutional abuse is more likely to be seen and reported.

\section{Types of Abuse}

\section{Physical Abuse}

Physical abuse is hitting, pulling, pinching, hurrying, or-pushing, or other maltreatingwith the intent to cause suffering, pain, or injury. Physical abuse is often used to punish, threaten, or control the elder person.

\section{Signs of physical abuse include:}

* injury that has not been cared for;

* injury that is inconsistent with explanation;

* pain from touching;

* cuts, puncture wounds, burns, bruises, welts;

* soiled clothing or bed;

* frequent use of hospital or health care; and/or

* doctor shopping.

The person who is being abused may appear:

* fearful;

* anxious;

* angry;

* withdrawn;

* non-responsive; and/or

* afraid to talk openly or may offer strange explanations for injuries.

The abusive caregiver may:

* prevent elder from seeing or talking to other people;

* act angry or aggressive;

* have a history of substance abuse or family violence;

* offer conflicting accounts of incidents; and/or

* withhold affection from the elder.

\section{Emotional or Psychological Abuse}

Emotional or psychological abuse occurs when the abuser verbally or non-verbally threatens, or humiliates the older adult. Victims of emotional or psychological abuse become withdrawn or depressed. They are at a higher risk of self-neglect because they lose hope and the will to live.

\section{Threats}

"Do as I say, or I'll put you in a home."

"You'll never see your grandchildren again."

"I'll just leave you here like this, then what would you do?" 


\section{Humiliation}

"You are just old and useless."

"I don't know why I bother."

"You're worse than a baby."

\section{Sexual Abuse}

Sexual abuse occurs when the abuser carries out any unwanted sexual contact. Sexual abuse includes unwanted touching, and all types of sexual assault or battery such as rape, sodomy, or forced nudity.

\section{Signs of sexual abuse include: \\ - $\quad$ bruises around the breasts or genital area; \\ - unexplained venereal disease or genital infections; \\ - Sexually transmitted disease/s (STDs) \\ - unexplained vaginal or anal bleeding; \\ - $\quad$ torn, stained, or bloody underclothing; and/or \\ - report of being sexually assaulted or raped.}

\section{Financial Abuse}

Financial abuse, also called financial exploitation, involves the unauthorized use of funds, property, or any resource of an older person. In many cases, the abuser simply steals from the older adult. Other times abusers may force the elder to 'sign-over' rights to property, checking accounts, or other assets. Too often elders are not aware of how much money they have or where their money goes. They may use deception or trickery to fool the elder as to where the money is going. The elder may also feel obligated to give the caregiver access to their funds in order to 'pay for their keep'.

\section{Financial exploitation may be happening when:}

- $\quad$ the elder frequently gives expensive gifts to the caregiver;

- the elder has numerous unpaid bills although there should be money to pay them;

- frequent checks are made out to 'cash';

- the caregiver refuses to spend money on the elder;

- the elder signs on a loan; and/or

- $\quad$ signatures on checks or legal documents do not match the elder's signature.

\section{Neglect and Self-Neglect}

Caregivers and family members who fail to provide adequately for the elder's basic needs are guilty of neglect. But the most common form of neglect is self-neglect. Self-neglect occurs when older adultsfail to take care of themselves. Neglect and self-neglect include failure to provide for the basic needs of everyday life such as food, clothing, shelter, medical care, and financial responsibility.

\section{Self Neglect}

Self-neglect is a serious problem in Florida. More than half of all calls to Adult Protective Services are to report self-neglect. In Florida, many older adults came from different states. Many of them become widowed after they move to Florida and are now alone. Their children and families live far away. Isolation, depression, and illness can lead to self-neglect. Becauseof poor health (as their physical and cognitive abilities decline)and limited resources, elders often fail to seek medicalattention or obtain essential home repairs, these factors may lead to hazardous living. 
Signs of self-neglect include:

- malnutrition;

- $\quad$ physically unclean and unkempt;

- excessive tiredness;

- dirty, ragged clothing;

- $\quad$ unmet medical and dental needs;

- refusing to take medicines or ignoring doctor's advice;

- filthy home; and/or

- failure to buy food or medications.

\section{Risk Factors of Abuse}

Most cases of elder abuse go unreported. That is why it is important to know who is most at risk of being abused and who is most at risk of becoming an abusive caregiver. It is also important to understand domestic and institutional settings that may contribute to the risk of elder abuse.

\section{Elders At Risk of Abuse}

- Female

- Drug /alcohol abusers

- History of abuse

- No friends or close family members

- Dependent on caregiver physically, emotionally, and/or financially

- Blames herself

- Physically or mentally ill

- Teasing or antagonizing behavior

- $\quad$ Lives away from neighbors

\section{Caregivers At Risk of Becoming Abusive}

- Expect elder to do more than she is able to do

- Current drug or alcohol problems

- Mentally ill

- Little or no experience as a caregiver

- Has money problems

- Feels alone

- Has also been a victim of abuse

Domestic Situations that Increase Risk of Abuse

- Isolated or rural setting

- Overcrowded home

- Pattern of domestic violence

- Not enough money to meet basic needs

- Lived together for more than 10 years

\section{Institutional Situations That Increase Risk of Abuse}

- High employee stress outside work

- High staff turnover

- Low wages

- Job frustration

- Not enough staff

- Severely ill patients 
- Cultural differences

- $\quad$ Lack of sympathy for the elderly

\section{Resources for Families and Caregivers}

Dos and Don'ts to Protect Yourself

\begin{tabular}{|l|}
\hline DO \\
- Keep in contact with family and friends. \\
- Participate in community activities \\
- Denever you can. \\
- each other. \\
- Keep regular appointments with your \\
- Be seen in the community. \\
- Ask your friends to visit you where you \\
- Have your own telephone. \\
- Kend and read your own mail. \\
- Keep your belongings neat and orderly. \\
\hline
\end{tabular}

\section{DON'T}

- Voluntarily give up control of your finances.

- Leave cash, jewelry, or valuables lying around.

- Accept personal care in exchange for signing over your property without consulting your own lawyer first.

- Lose contact with old friends and neighbors if you move.

- Allow anyone else to keep details of your finances.

\section{Florida Resources}

\section{Older Floridians Handbook}

This guide was written for Floridians 60 and over. It contains legal information as well as contacts in addition to other useful information. It may be accessed online at Older Floridians Handbook

You can request a printed version of this handbook, if you call (305)358-2081 or write to:

Florida Justice Institute, Inc.

2870 First Union Financial Center

200 South Biscayne Boulevard

Miami, Florida 33131-2310

\section{Elder Update}

Elder Update is an on-line newspaper published by the Florida Department of Elder Affairs (DOEA). It is updated bi-monthly and can be accessed on the web. You will need Acrobat Reader(C (a free download at the Elder Update Web site or from www.adobe.com) in order to read the issues of the newspaper.

Elder Update

http://www7.myflorida.com/doea/healthfamily/learn/elderservices/doeaelderupdate.htmli

or, for those residing in Florida, you may order this free newspaper by sending your name, address, city, state (Florida ONLY), and zip code to:

The Florida Department of Elder Affairs

Elder Update Subscriptions

P.O. Box 6750

Tallahassee, Florida 32314-6750

Elder Update is also available in Braille or on cassette tape. To order one of these formats, call: 1-800-226-6075. 


\section{Florida Department of Elder Affairs}

The Florida Department of Elder Affairs (DOEA) is responsible for providing programs and services for older Floridians through the Area Agencies on Aging. You can contact the Florida DOEA by writing, calling, or on the Web.

Florida Department of Elder Affairs

4040 Esplanade Way, Suite 315

Tallahassee, Florida 32399-7000

(850) 414-2000 - Fax (850) 414-2004

TDD (850) 414-2001

http://elderaffairs.state.fl.us/,

\section{How To Report Abuse}

Florida Statute 415 covers reporting suspected elder abuse. That means that anyone who suspects that an elder is being abused is responsibly for notifying the proper authorities.

Florida has established a 24-hour hotline that will accept reports of elder abuse nationwide.

\author{
All domestic and institutional elder abuse \\ should be reported by calling 1-800-96-ABUSE - \\ that's 1-800-962-2873.
}

\author{
To Report Domestic Abuse in Florida \\ 1-800-96-ABUSE \\ $1-800-962-2873$ \\ TDD 1-800-453-5145
}

\section{Florida Long-term Care Ombudsman}

To report institutional abuse in Florida contact the Long-term Care Ombudsman Council near you to investigate. Addresses and local telephone numbers for several Florida county Ombudsman Councils may be found by pointing your Web browser to: hhttp://www7.myflorida.com/doea/healthfamily/learn/elderservices/doeaelderupdate.html'

\section{To Report Institutional Abuse in Florida}

If you do not have access to the Internet or your county is not listed, you may also call 1-888831-0404 to get information regarding the closest Long-term Care Ombudsman.
Florida Long-term Care Ombudsman $1-888-831-0404$

To Report Abuse Outside of Florida Eldercare Locator $1-800-677-1116$

\section{References}

Brungardt, G. (1990). Veterans Administration Medical Center. Kansas City, Missouri

Elder Abuse Awareness Kit: A resource kit for protecting older people and people with disabilities (2001). National Association of Adult Protective Services Administrators.

Elder Abuse: The basics (2002). Published by the National Center on Elder Abuse (NCEA). Available at http://Www.elderabusecenter.org/basic/index.htmli

Department of Elder Affairs (2002) My Florida - Health and Human Services: Department of Elder Affairs. Available on-line at http://elderaffairs.state.fl.us/'

Starr, D. and Wilken, Carolyn. (1994). Elder Abuse. Kansas Cooperative Extension Service. Manhattan, Kansas.

Wilken, Carolyn. (1992). Evergreen. Through The Seasons Of Life. A newsletter about Adult Development and Aging. Vol. 2(5). Kansas Cooperative Extension Service, Manhattan, Kansas. 